Saudi Journal of Medical and Pharmaceutical Sciences

Abbreviated Key Title: Saudi J Med Pharm Sci ISSN 2413-4929 (Print) |ISSN 2413-4910 (Online) Scholars Middle East Publishers, Dubai, United Arab Emirates Journal homepage: https://saudijournals.com/sjmps

Original Research Article

\title{
Microbial Analysis of Selected Brands of Whitening Creams
}

\author{
Abdul Aleem ${ }^{1 *}$, Mehran Khan ${ }^{1}$, Usman Abid ${ }^{2}$, Muhammad Faisal Ishfaq ${ }^{1}$, Abdul Rouf ${ }^{1}$, Talha Jamshaid ${ }^{1}$
}

${ }^{1}$ Department of Pharmaceutics, The Islamia University of Bahawalpur, Pakistan

${ }^{2}$ Department of Pharmaceutics, Bahauddin Zakariya University, Pakistan

DOI: $10.36348 /$ sjmps.2020.v06i02.006
*Corresponding author: Abdul Aleem

Abstract

Background: Whitening creams are most commonly used by both men and women for beautifying and cleaning. These creams are not commonly sterile and contaminated during different stages of formulation from manufacturing to consumer. Pseudomonas aeruginosa, some gram negative bacteria and Staphylococcus aureus are involved in the contamination of cosmetic products. The use of microbial contaminated whitening cream may become health hazard to consumers. Objective: Microbial analysis of selected brands of whitening creams commonly used by the community of Pakistan. Methods: Four well-known brands of whitening creams were chosen for microbiological analysis and assigned coding as W-A, W-B, W-C and W-D respectively. Conventional culture were used for microbial analyze. Differential $\&$ Selective Media used for Identification of Microorganism and further confirmation of microbes were subjected by biochemical tests. Results: All four brands were observed contaminated with bacteria up to $10^{6} \mathrm{CFU} / \mathrm{g}$ that finally more than the U.S.P. or F.D.A. recommended limit of less than $10^{3} \mathrm{CFU} / \mathrm{g}$ for non-eye area. Growth of Klebsiella sp., Staphylococcus sp., and Pseudomonas sp was noted as well. Fungal population was not observed in any brand of whitening creams. Escherichia coli and actionmycetes were not present in all the samples. Klebsiella sp. and Pseudomonas sp. were detected in all brands within a range of 1. Conclusions: According to current microbial analysis there is higher load of total viable microbes in all samples. These contaminated products are health hazards to consumers. There should be checking during fabrication, packaging and storing of the cosmeceuticals brands by the regulatory bodies and intensive care the operation as well as the supply of cosmetics products among the health-care stores.

Keywords: Microbial Analysis, Whitening creams, Health Hazards, Skin Infections, Bacteria. Copyright @ 2020: This is an open-access article distributed under the terms of the Creative Commons Attribution license which permits unrestricted
use, distribution, and reproduction in any medium for non-commercial use (NonCommercial, or CC-BY-NC) provided the original author and source
are credited.

\section{INTRODUCTION}

The use of whitening creams by both men and women are common old practice globally since from 16 th century [1]. The use of whitening cream is associated with beauty in Asian countries like Korea, Japan, India China Bangladesh and Pakistan while in Africa people use it for various purposes including economic motivations, beautiful and psychological [26]. Skin lightening agents are also utilized for antiaging and skin-fairness cosmetics products and gaining importance clinically and cosmetically [7]. Whitening agents consist of corticosteroids mercury-salts hydroquinone, corticosteroids lighten skin by inhibit the process of melanocyte maturation [8].
Pharmaceutical products prone to microbial contamination during manufacturing, packaging and storage conditions particularly in developing countries [9-13]. Cosmetic products, used mainly for cleaning and beautifying and protecting [13], may also undergo contamination by a variety of microbes during manufacturing process and storage same as pharmaceuticals products $[14,15]$.

Undeniably, in addition to pharmaceutical health care medicinal products, Cosmetics items are susceptible to microbial attack since these products are non-sterile $[16,17,15] \quad$ Cosmetics products are contaminated by several bacteria like Pseudomonas aeruginosa, some gram-negative bacteria and Staphylococcus aureus [16,17]. Quality of cosmetics products are also compromised by certain yeasts and molds [17]. 
The degree of microbial Spoilage mainly due to the unsanitary handle of bulk raw material during process of production and due to inadequate in process check and substandard storing or delivery [18-20]. The utilization of microbial contaminated cosmetics products may cause a health risk among consumers as obvious from one of the earliest and most dramatic incidences of microbial spoilage of a cosmetic. In New Zealand, the death of four babies was endorsed to the consumers of talcum powder mixed with Clostridium tetuni in 1946 [21], Klebsiella pneumoniae observed to infect hand creams causing Septicaemia in 1967[22], contamination of eye cosmetics P. aeruginosa [23] and finally in 1983, Pseudomonas stutzeri contaminate aqueous soap. After that microbiological experiments reveal that this contamination is due to unhygienic handling of ingredients during manufacturing [24-26]. In many under developed countries microbiological contamination of cosmetics have been largely reported $[10,14]$. like pharmaceutical the reports on quality on cosmetics are not available[27, 28, 25].

Different cosmetics products like face washes, creams, whitening cream and soaps, all are found contaminated with bacteria and fungi. However, certain limit recommended by FDA and BP/USP for microorganism. To maintain safety of cosmetics product regulatory bodies including FDA and USP has guidelines for acceptable limits of microorganisms for microbiological analysis. According to these guidelines the degree of contamination in cosmetics brands with pathogenic bacteria should not go above the FDA and limit the United States Pharmacopoeia (USP) limit (non-eye area less than $1000 \mathrm{cfu} / \mathrm{g}$ and for eye area less than $10^{2} \mathrm{cfu} / \mathrm{g}$ ) otherwise there are chances of many skin problems. Eczema, acne, dyschromia and scabies are mainly skin diseases have been reported by topical application of cosmetics exceeding microbial bioburden limits [29]. In order to ensure the quality of cosmetics products as well as public health protection of consumers there should be reliable and consistent microbial monitoring throughout fabrication, covering, storing of the cosmeceuticals [30,31].

The topical use of skin whitening creams has been increased in last few decades. Most of the cosmetics are not sterile and they are made of nonsterile raw material. So, there is microbial content in Whitening creams which may cause contamination of products and responsible many serious health risks for consumers. Although, preservatives are added to products to control microbial growth in cosmetics products but no expiry date mention on mostly cosmetics products. So, they lose preservative activity and become risk for consumers. The objectives of this research were to ascertain the incidence of the microbial contamination of different skin fairing creams brands. The magnitude and type of microbial contaminants were also determined

\section{Materials ANd Methods Sample's preparation and dilutions}

4 leading brands of whitening creams were included in this study. These are most commonly used by people. All samples were obtained from famous selling outlet in Lahore Market with appropriate dates of manufacturing and expiry date, in January 2019.According to USP Chapter 61 Under "Microbial enumeration tests" sample prepared. For dilution Phosphate buffer saline (BPS) was used.1g of sample was mixed with sterile Tween 80 which is not more than of its weight and warm at temperature which is no more than $40^{\circ} \mathrm{C}$. Temperature sustained using water bath. 1:10, 1:100 and 1:1000 dilution of product was prepared by adding sufficient amount of pre-warmed Phosphate buffer saline.

\section{Microbial Enumeration}

Microbial cultures from sample were culture on nutrient agar plates and potato dextrose agar plate for enumerating total viable count and fungal's load estimation respectively and incubate for 24 hours at $37^{\circ} \mathrm{C}[28]$.

For specific pathogen and actinomycetes for enumeration of Pseudomonas sp., actinomycetes, Escherichia coli, Staphylococcus sp., and Bacillus sp. Suspension was spread on cetrimide agar, Bennet agar, MacConkey agar, mannitol agar and Phenol red agar respectively. Eosine-methylene blue (EMB) agar was used for confirmation of E.Coli by obervation of dark center and green metallic sheen [32]. Biochemical testing was used for further identification [28].

\section{RESULT AND DiSCUSSION}

Cosmetics contain favorable nutrients which support the growth of microorganism that's why they are not supposed to be sterile [18]. The prevalence of skin disease due to inadequate sanitation, the consumption if microbiological contaminated water and unhygienic environment is common in developing countries[24].

Therefore, cosmetic products should be free from pathogen and total aerobic bacterial load should be below limits as they are unable to cause any skin infections[33]. Maintenance of good quality of cosmetics product is important. To avoid the chance of skin infection microbiological analysis of finishing product is necessary to achieve good quality product. In present study different whitening cream brands commonly used by people of Pakistan were analyzed for microbial contamination for assessing the actual situation. 4 brands of local and multinational whitening creams were selected that are most commonly used by people for facial whitening. 
All the brands especially locally manufactured showed higher concentration of total viable bacteria up to $10^{6} \mathrm{cfu} / \mathrm{g}$ which ultimately cross the USP or FDA limit of $<10^{3} \mathrm{cfu} / \mathrm{g}$ for non-eye area. Among the pathogenic bacteria which were confirmed by biochemically test Staphylococcus specie were present in all sample. E. coli and actinomycetes were completely absent in all the samples. Klebsiella specie and Pseudomonas sp. were detected in all brands within a range of $10^{1} \mathrm{cfu} / \mathrm{g}$. No fungal population was detected in any whitening cream sample (Table4.1).
Total bacteria and pathogenic bacteria were found higher in local brands as compared to multinational brand. It may be due to environmental condition and unhygienic handling and raw material which are responsible for microbial growth [34, 14, 35]. Sometimes storage temperature, poor activity of preservative, $\mathrm{PH}$ of product, availability of oxygen and chemicals such as lipids, alcohol, polysaccharides, glucoside etc. also responsible for microbial growth (Commonly and Dhaka) [36, 37].

Table-3-1: Population of Pathogenic Microorganisms in various brands of Whitening Creams (cfu/g)

\begin{tabular}{|c|c|c|c|c|c|c|c|c|}
\hline Sample & $\begin{array}{l}\text { TVB } \\
(\mathrm{cfu} / \mathrm{g})\end{array}$ & $\begin{array}{c}\text { Pseudomonas } \\
\text { Specie } \\
(\mathrm{cfu} / \mathrm{g})\end{array}$ & $\begin{array}{c}\text { Klebshialla } \\
\text { specie } \\
\text { (cfu/g) }\end{array}$ & $\begin{array}{l}\text { Staphylococcus } \\
\text { specie (cfu/g) }\end{array}$ & $\begin{array}{l}\text { E.coli } \\
\text { (cfu/g) }\end{array}$ & $\begin{array}{l}\text { Bacillus } \\
\text { specie } \\
\text { (cfu/g) }\end{array}$ & $\begin{array}{l}\text { Actinomycetes } \\
(\mathrm{cfu} / \mathrm{g})\end{array}$ & $\begin{array}{l}\text { Total } \\
\text { fungal } \\
\text { count }\end{array}$ \\
\hline Tibbet & $5 \times 10^{6}$ & $3.5 \times 10^{1}$ & $5.29 \times 10^{1}$ & $8.25 \times 10^{1}$ & 0.00 & $5.0 \times 10^{1}$ & 0.00 & 0.00 \\
\hline Ponds & $1.4 \times 10^{4}$ & $2.2 \times 10^{1}$ & $1.00 \times 10^{1}$ & $1.2 \times 10^{1}$ & 0.00 & $4.3 \times 10^{1}$ & 0.00 & 0.00 \\
\hline $\begin{array}{l}\text { Fair \& } \\
\text { lovely }\end{array}$ & $6.3 \times 10^{5}$ & $3.7 \times 10^{1}$ & $1.25 \times 10^{1}$ & $4.2 \times 10^{1}$ & 0.00 & $5.3 \times 10^{1}$ & 0.00 & 0.00 \\
\hline Handsome & $8.2 \times 10^{5}$ & $2.9 \times 10^{1}$ & $4.29 \times 10^{1}$ & $3.25 \times 10^{1}$ & 0.00 & $3.2 \times 10^{1}$ & 0.00 & 0.00 \\
\hline
\end{tabular}

Table-3-2: Confirmatory biochemical tests for the isolation of Pathogenic Bacteria

\begin{tabular}{|c|c|c|c|c|c|}
\hline Supposed Organisms & Indole Test & $\begin{array}{c}\text { Citrate } \\
\text { Test }\end{array}$ & $\mathbf{H}_{2} \mathbf{S}$ & Motility Test & Oxidase test \\
\hline Staphylococcus specie & - & + & + & + & - \\
\hline Klebsiella specie & - & - & - & - & + \\
\hline Pseudomonas specie & - & + & - & - & - \\
\hline Bacillus specie & - & - & - & - & - \\
\hline
\end{tabular}

\section{CONCLUSION}

Current study showing a higher load of microorganisms in different commonly used whitening creams. The higher population of total viable bacteria brought indicative mark on the detrimental effect on consumer health of using such non sterile cosmetics and strong evidence for further research on other cosmetics products to reduce the burden of skin diseases. Many People use whitening creams unaware of potential harms due to contamination of such products. There is chance of microbial contamination and facial skin infections. So, there should be necessary regular training for manufacturing companies and improved Good Manufacturing Practice.

There should be monitoring during manufacturing, packing and storing of the cosmeceuticals by the governing bodies, monitoring the procedure and the delivery of cosmetic products among the health-care stores. Present data significantly presenting indications not only in Pakistan but also in developing countries where such non-sterile cosmetic products are commonly used. More attentions should be enforced on the maintenance of sterile manufacturing situation, appropriate management of all raw materials and lastly, their storing and delivery to health-care stores.

\section{REFERENCES}

1. Arudou, D. (2013). An introduction to japanese society's attitudes toward race and skin color. The melanin millennium. Springer, 49-69.

2. Alghamdi, K. (2010). The use of topical bleaching agents among women: A cross- sectional study of knowledge, attitude and practices. Journal of the European Academy of Dermatology and Venereology, 24: 1214-1219.

3. De Souza, M. M. (2008). The concept of skin bleaching in africa and its devastating health implications. Clinics in Dermatology, 26: 27-29.

4. Hall, R. E. (2013). The bleaching syndrome: Western civilization vis-à-vis inferiorized people of color. The melanin millennium. Springer, 1-18.

5. Hunter, M. (2007). The persistent problem of colorism: Skin tone, status, and inequality. Sociology Compass, 1: 237-254.

6. Olowu, A., \& Ogunlade, O. (2013). Pathophysiology and psychopathology of skin bleaching and implications of skin colour in africa. The melanin millennium. Springer, 39-48.

7. Raj, S., Jose, S., Sumod, U., \& Sabitha, M. (2012). Nanotechnology in cosmetics: Opportunities and challenges. Journal of pharmacy \& bioallied sciences, 4: 186. 
8. Briganti, S., Ottaviani, M., Picardo, M., \& Lacour, J. P. (2006). Chemical, pharmacologic, and physical agents causing hypomelanoses. The Pigmentary System: Physiology and Pathophysiology, 669-685.

9. Fatema, K., Chakraborty, S. R., Sultana, T., Rahman, M. M., Kamali, N. M., Das, K. K., \& Noor, R. (2014). Assessment of microbiological quality of the pediatric oral liquid drugs. Journal of Pharmacognosy and Phytochemistry, 3.

10. Hossain, M. A., Raton, K. A., \& Noor, R. (2014). Microbiological quality investigation of eye and ear ointments available in bangladesh. Journal of Pharmacognosy and Phytochemistry, 3.

11. Quaiyum, S., Tanu, N. I., Sharmin, M., Laboni, P., Munna, M. S., Das, K. K., Acharjee, M., \& Noor, R. (2014). Microbiological contamination and antibacterial traits of common oral herbal medicinal products within dhaka metropolis. European Journal of Medicinal Plants, 4: 872.

12. Rana, J., Sultana, T., Das, K. K., \& Noor, R. (2014). Microbiological analysis of topicals available in bangladesh. Int J Pharm Pharma Sci. 6: 330-2.

13. Raton, K. A., Hossain, M. A., Acharjee, M., \& Noor, R. (2013). Assessment of microbiological quality and the anti-bacterial traits of sterile liquids used for medication of eye and ear infections in bangladesh. Am J Pharma Health Res. 1: 67-75.

14. Khanom, S., Das, K. K., Banik, S., \& Noor, R. (2013). Microbiological analysis of liquid oral drugs available in bangladesh. Int J Pharm Pharma Sci, 5: 479-482.

15. Smart, R., \& Spooner, D. (1972). Microbiological spoilage in pharmaceuticals and cosmetics. J Soc Cosmet Chem. 23: 721-737.

16. Elaine, B. (1989). The hazards of cosmetics. New York, Hasrper and Row. 1-5.

17. Jimenez, L., Ignar, R., Smalls, S., Grech, P., Hamilton, J., Bosko, Y., \& English, D. (1999). Molecular detection of bacterial indicators in cosmetic/pharmaceuticals and raw materials. Journal of Industrial Microbiology and Biotechnology, 22: 93-95.

18. Commonly, P. O. M. O. I., \& Dhaka, U. C. S. I. Journal of pharmaceutical and scientific innovation.

19. Mwambete, K. D., Temu, M. and Fazleabbas, F. S. (2009). Microbiological assessment of commercially available quinine syrup and water for injections in dar es salaam, tanzania. Tropical Journal of Pharmaceutical Research, 8.

20. Nagarnaik, M., Sarjoshi, A., Linge, P., Bhore, S., \& Pandya, G. (2015). A microbial study of some cosmetics and raw materials used in personal care products in urban area. Research Journal of Topical and Cosmetic Sciences, 6: 48.

21. Anelich, L., \& Korsten, L. (1996). Survey of micro- organisms associated with spoilage of cosmetic creams manufactured in south africa. International journal of cosmetic science, 18: 2540.

22. Morse, L. J., Williams, H. L., Grenn Jr, F. P., Eldridge, E. E., \& Rotta, J. R. (1967). Septicemia due to klebsiella pneumoniae originating from a hand-cream dispenser. New England Journal of Medicine. 277: 472-473.

23. Wilson, L. A., Julian, A., \& Ahearn, D. G. (1975). The survival and growth of microorganisms in mascara during use. American journal of ophthalmology, 79: 596-601

24. Manu-Tawiah, W., Brescia, B. A., \& Montgomery, E. R. (2001). Setting threshold limits for the significance of objectionable microorganisms in oral pharmaceutical products. PDA journal of pharmaceutical science and technology. 55: 171176.

25. Noor, R., Zerin, N., \& Das, K. K. (2015). Microbiological quality of pharmaceutical products in bangladesh: Current research perspective. Asian Pacific Journal of Tropical Disease, 5: 264-270.

26. Noor, R., Zerin, N., Das, K. K., \& Nitu, L. N. (2015). Safe usage of cosmetics in bangladesh: A quality perspective based on microbiological attributes. Journal of Biological ResearchThessaloniki. 22: 10.

27. Akon, T., Das, K. K., Nitu, L. N., \& Noor, R. (2015). Demonstration of in vitro antibacterial activity of the popular cosmetics items used by the dhaka locality. Asian Pacific Journal of Tropical Disease, 5: S121-S126.

28. Das, K., Fatema, K., Nur, I., \& Noor, R. (2013). Prevalence of microorganisms in commonly used cosmetics samples in dhaka metropolis. J Pharma Sci Inno, 2: 7-9.

29. Becks, V. E., \& Lorenzoni, N. M. (1995). Pseudomonas aeruginosa outbreak in a neonatal intensive care unit: A possible link to contaminated hand lotion. American journal of infection control, 23: 396-398.

30. Brannan, D. K., \& Dille, J. (1990). Type of closure prevents microbial contamination of cosmetics during consumer use. Appl. Environ. Microbiol, 56: 1476-1479.

31. Sccs, E. (2012). The sccs's notes of guidance for the testing of cosmetic substances and their safety evaluation-8th revision. SCCS/1501/12. Available online: http://ec. europa. eu/health ....

32. Urmi, N., Ahmed, T., Acharjee, M., Das, K., \& Noor, R. (2013). Microbiological analysis and detection of antibacterial activity of salad vegetables found in dhaka metropolis. Bangladesh. J Pure Appl Microbiol.

33. Siegert, W. (2012). Microbiological quality management for the production of cosmetics and detergents. SOFW Journal-Seifen Ole Fette Wachse, 138: 30. 
34. Beys, L., \& Hoest, B. (1971). Investigation for staphylococci in foods, dietetic products and oral drugs. Rev J Food Protec, 25: 26-33.

35. Rowe, R. C., Sheskey, P., \& Quinn, M. (2009). Handbook of pharmaceutical excipients, Libros Digitales-Pharmaceutical Press.

36. Campana, R., Scesa, C., Patrone, V., Vittoria, E., \& Baffone, W. (2006). Microbiological study of cosmetic products during their use by consumers: Health risk and efficacy of preservative systems. Letters in applied microbiology, 43: 301-306.

37. Dashen, M. M., Chollom, P. F., Okechalu, J. N., \& Ma'aji, J. A. (2011). Microbiological quality assessment of some brands of cosmetics powders sold within jos metropolis, plateau state. 